\title{
DEVELOPMENT OF A RAPID-OPERATING
}

\section{PLUGGING METER}

\section{AEC Researcb and Development Report}

\section{ATOMICS INTERNATIONAL} A DIVISION OF NORTH AMERICAN AVIATION, INC. 


\section{DISCLAIMER}

Portions of this document may be illegible in electronic image products. Images are produced from the best available original document. 


\section{LEGAL NOTICE}

This report was prepared as an account of Government sponsored work. Neither the United States, nor the Commission, nor any person octing on behalf of the Commission:

A. Makes any warranty or representation, express of implied, with respoct to the accuracy, complataness, or usefulnass of the information containad in this report, or that the use of any information, opporatus, method, or process disclosed in this report moy not infringe privately owned rights; o

B. Assumes ony liobilities with espect to the use of, or for damages resulting from the use of informotion, apporatus, mothod, of process disclosed in this report.

As used in the above, "person acting on behalf of the Commission" includes ony am. playee or contractor of the Commission is the oxtem that such employes or contracter proparas, handies or distributes, or providos access to, any information pursuant to his amployment or controct with the Commission.

Price $\$ 0$ so

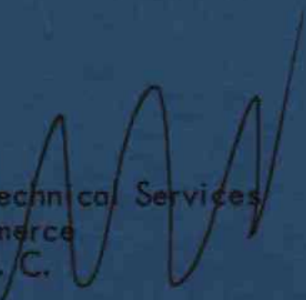

Worment of Co m. C. 


\section{DEVELOPMENT OF A RAPID-OPERATING}

PLUGGING METER

By

K. DAVIS

\section{ATOMICS INTERNATIONAL}
A DIVISION OF NORTH AMERICAN AVIATION, INC. P.O. BOX 309 CANOGA PARK, CALIFORNIA

CONTRACT: AT(11-1)-GEN-8

ISSUED: 


\section{(11)}

\section{DISTRIBUTION}

This report has been distributed according to the category "ReactorsGeneral" as given in "Standard Distribution Lists for Unclassified Scientific and Technical Reports" TID-4500 (15th Ed.), August 1, 1959. A total of 625 copies was printed. 


\section{AI}

\section{CONTENTS}

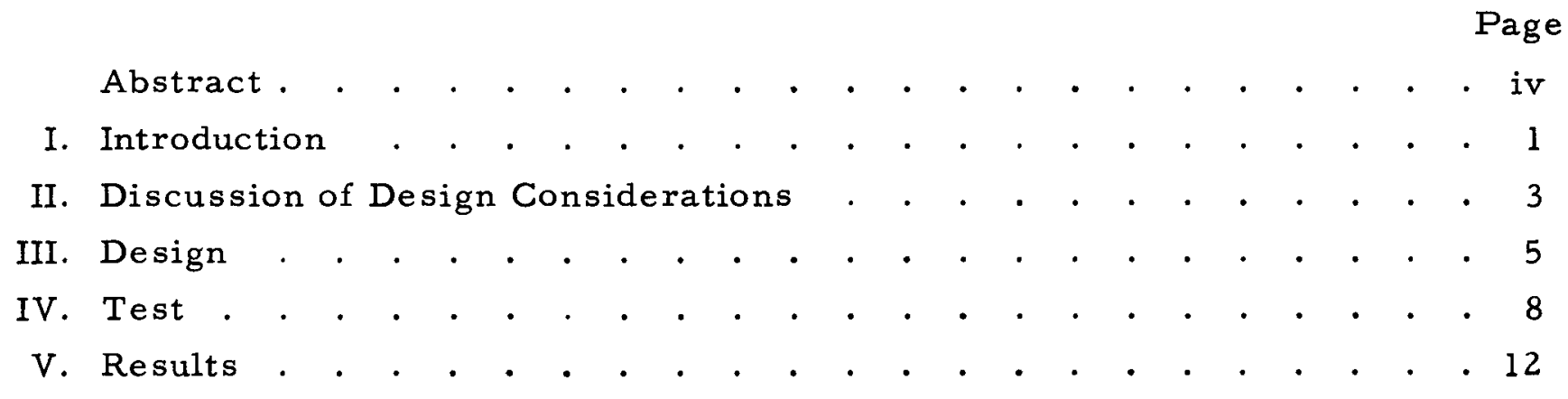

FIGURES

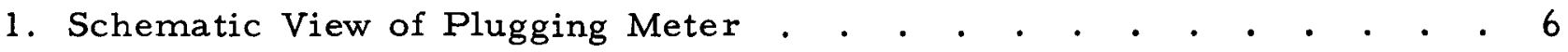

2. Cutaway View of Plugging Meter . • . • • • • • • • • . . $\quad 7$

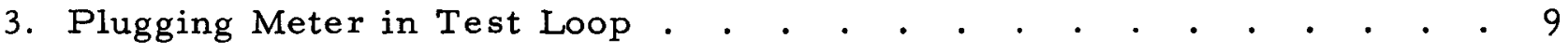

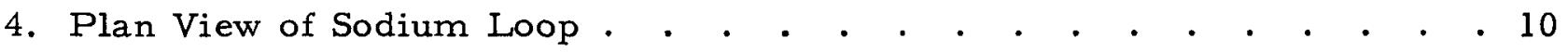

5. Recorder Display of Temperature and Flow in the Plugging

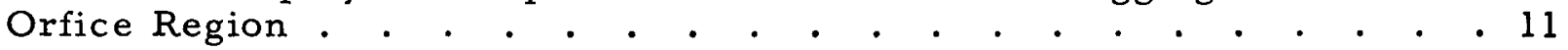

6. Variation of Plugging Temperature with Sodium Oxide Concentration . . . . . . . . . . . . . . . . . . . 13 


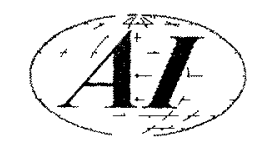

\begin{abstract}
An air-cooled plugging meter for rapid determination of sodium oxide concentration in liquid sodium was tested in an experimental system. Approximately 200 plugging tests were performed, with results indicating good repeatability and a relatively fast operating time compared to other plugging meters. A typical operating time for making a determination with a system temperature of $725^{\circ} \mathrm{F}$ was 5 minutes.
\end{abstract}




\section{(4)}

\section{INTRODUCTION}

Commercial sodium contains small amounts of impurities and this impurity level usually increases during the initial charging and the subsequent circulation of sodium in a coolant system. The high chemically reactive nature of sodium coupled with the prevalence of oxygen make sodium oxide one of the most unavoidable contaminants.

The oxide is soluble in sodium to an extent that is proportional to the sodium temperature. Hence, in a high-temperature system using liquid sodium as a coolant, large quantities (in the order of hundreds of ppm) of oxide can be carried in solution throughout the system. The presence of sodium oxide is detrimental because it accelerates the corrosion rate of the materials it contacts. Another detrimental effect of more immediate consequence in operations is sodium oxide precipitation in the relatively cool regions. The accumulation of this precipitate, particularly in narrow passages, causes plugging which results in interference with flow.

For this reason, in a nuclear reactor employing sodium as coolant, oxide concentration must be kept very low. So far as plugging is concerned, a concentration below about $10 \mathrm{ppm}$ is considered satisfactory. Several very effective means of removing oxide from sodium have been devised and successfully used.

During the initial filling and subsequent operation of a sodium system, the oxide concentration must be measured to ensure satisfactory operation and guide the oxide trapping requirements.

A number of methods for measuring sodium oxide concentration have been devised which are based upon chemical analytical techniques. These are not well suited to the function of monitoring the oxide concentration in a sodiumcoolant-process system. Another method uses the temperature-solubility relationship of sodium oxide in sodium in the familiar plugging meter. This device has become widely used in sodium systems. It consists of a section of pipe fitted with a flow restriction (usually a perforated plate) across the pipe. Sodium flowing through this pipe section is cooled in a heat exchanger located upstream relative to the orifice until the temperature reaches a value such that the 


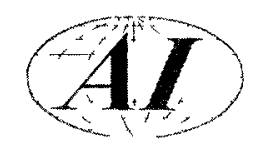

oxide precipitates and plugs the orifices. A flowmeter in the line signals the occurence of plugging, and a thermocouple at the orifice indicates the temperature at which plugging occurs. This temperature of plugging corresponds to a certain value of oxide concentration which can be determined by referring to a calibration curve relating oxide concentration to temperature.

While the plugging meter method is basically simple and appears to be ideal, practical problems in its use have engendered some elaboration of the elementary design. Unfortunately some of the improvements have resulted in the creation of new problems.

The objective of the effort described in this report was to develop a model of a plugging meter capable of rapid, accurate, operation, suitable for monitoring the sodium oxide concentration in nuclear-reactor-sodium-coolant systems. 


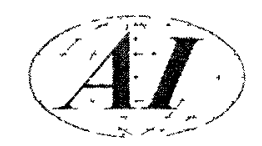

\section{DISCUSSION OF DESIGN CONSIDERATIONS}

Although the preferential precipitation of oxide in cool regions is detrimental, it is fortunate that the phenomenon is useful as a means of measurement. Essentially, the measurement is accomplished by inducing oxide precipitation at a convenient location.

Tests performed on earlier models of plugging meters revealed four objectionable features: (a) time required for running an oxide plugging measurement was an hour or more; (b) data were not sufficiently reproducible; (c) premature precipitation of oxide occurred upstream of the plugging-orifice; and (d) unplugging often required considerable time and special effort incompatible with practical coolant-system operation.

The time required for making a plugging measurement is a function of the cooling rate. To keep cooling equipment size reasonable, a small sodium flow rate is therefore required.

To make the data reproducible, it is necessary to minimize extraneous variables. Interference by other soluble contaminants, particularly sodium hydride, may influence the value obtained in oxide plugging. Little can be done to eliminate this interference except to eliminate the hydride. However, so far as practical coolant-system operations are concerned, plugging of a coolant passage, whether from oxide or hydride is objectionable. So far as the plugging meter readings are concerned, it makes a difference whether the plugging is due to oxide or hydride because the temperature - solubility relationships of the two substances differ. The presence of both in varying proportions can cause seeming anomalies in the oxide plugging values. This effect may be one factor contributing to the inaccuracies attributed to plugging meters.

Another factor to be considered is the variation in oxide concentration at the plugging-orifice caused by premature precipitation of oxide in the economizer or other cool region upstream. As a result of this premature precipitation, the sodium arriving at the orifice would be relatively clean if it were stripped of oxide upstream; however, depending upon several operational factors, this oxide may be released from the cool surfaces and then reprecipitated upon the orifice plate. This would cause erratic plugging results. Ideally, substantially 


\section{(A)}

all the oxide entering the plugging meter should be available at the plugging-orifice to precipitate in accordance with the prevailing temperature - solubility relationship. To achieve this, the plugging meter should have a very short, lowvolume cooling section preceding the orifice plate and the flow rate should be low. This concept is compatible with the previously stated objective of reducing the sodium flow rate to achieve speed in cooling.

Sometimes unplugging is a difficult process, particularly in circumstances in which the plug contains a high proportion of contaminants. Application of heat sufficient to dissolve the plug is the usual remedy but it is not always easy to deliver sufficient heat to the plug. The unplugging may be facilitated by having the hot, relatively clean process stream sodium flow through the region. An obvious remedy is an orifice which may be expanded to disturb the mechanical support of the oxide so that it may be flushed away through the enlarged orifice with fresh hot sodium. 


\section{AI}

\section{DESIGN}

The ideas presented in Section II were the basis for the design of the plug ging meter illustrated in Figure 1.

The process stream sodium enters the central tube and flows down toward the plugging-orifice. Heat from the sodium in this central tube flows to the air-cooled sodium in the outer tube. The cooling air is directed onto the plugging-orifice end of the economizer so that the oxide concentration is greatest in the vicinity of the plugging-orifice. The plugging-orifice is shaped as shown in Figure 1. The central hole is 1/8 in. in diameter and four adjacent holes are 50 mils in diameter. The size of the central hole is arbitrary but the choice of 50-mil diameter for the adjacent holes follows conventional practice. In normal operation, the central hole is covered by the cone-shaped point of the central rod so that the sodium passes through the outer four holes only. When the temperature is lowered below the temperature corresponding to saturation at the particular oxide concentration, precipitation will occur. This causes clogging or plugging of the small holes and hence stops the flow of sodium which is indicated by the flowmeter. A record is made of the temperature, and the orifice is then unplugged by withdrawal of the pointed rod covering the central hole in the orifice plate. The motion of the rod is controlled by the solenoid. Concurrently with the rod withdrawal, heat is applied to the sodium to accelerate dissolving the oxide. The plugging meter is mounted vertically so that the normal (down) rod position is restored by gravity.

A model, constructed according to the design outlined above, is shown in Figure 2. It s overall width including flow meter and pipe stubs, is approximately 13 in. and overall length was approximately $30 \mathrm{in.}$ The total weight is approximately $25 \mathrm{lb}$.

The power required is $1000 \mathrm{w}$ at $230 \mathrm{v}$ for the heater, $55 \mathrm{w}$ at $110 \mathrm{v}$ for the blower and $35 \mathrm{w}$ at $50 \mathrm{v}$ for the solenoid.

Flow is indicated by a flow meter having a sensitivity of $6 \mathrm{mv} / \mathrm{gal} / \mathrm{min}$.

Temperature in the orifice region is measured by a chromel alumel thermocouple which is mounted in a thimble protruding into the sodium. 


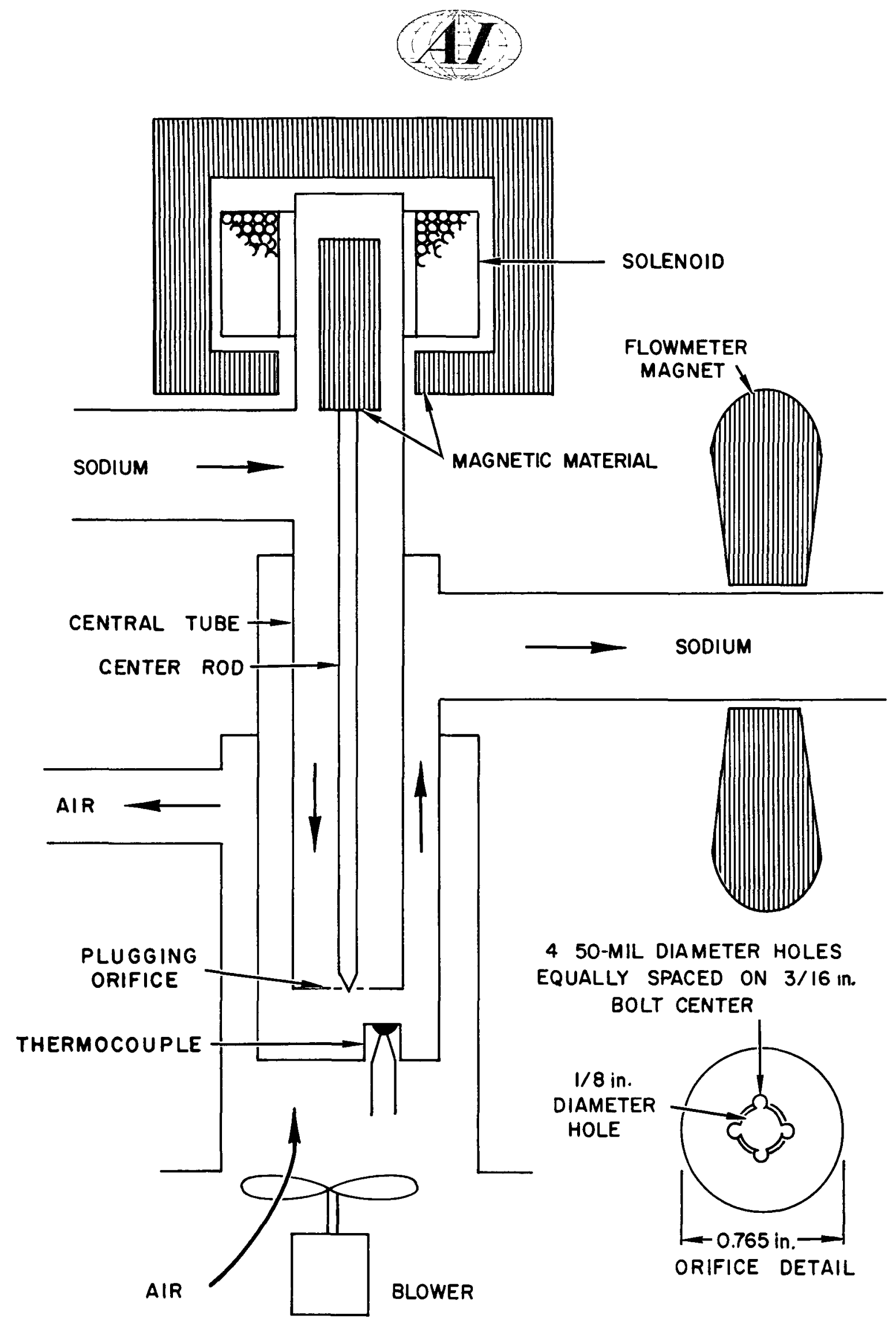

Figure 1. Schematic View of Plugging Meter 


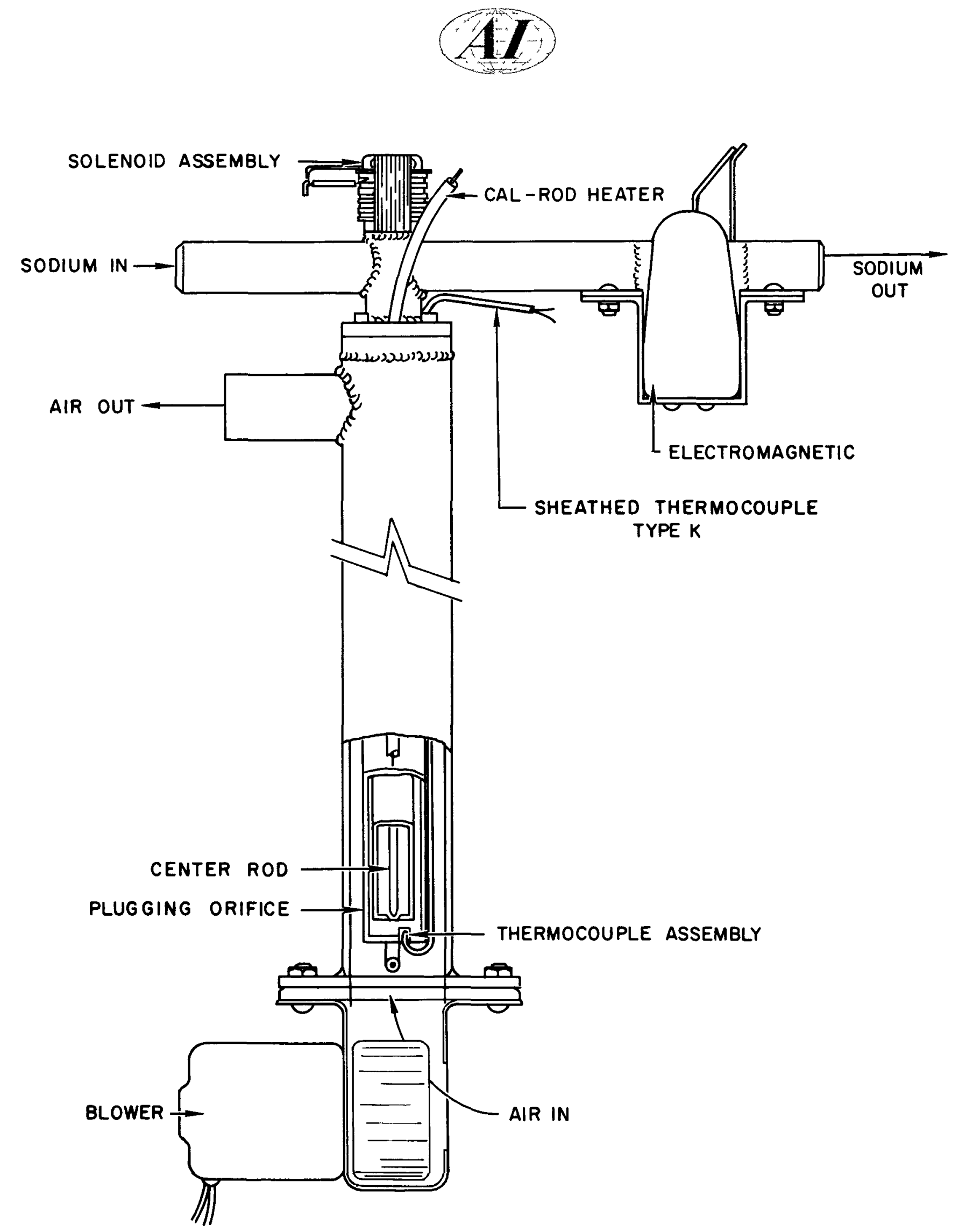

Figure 2. Cutaway View of Plugging Meter 


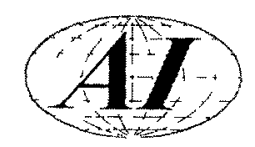

\section{TEST}

The plugging meter was tested in the small loop shown in the photograph of Figure 3 and the diagram of Figure 4. A reservoir, an electromagnetic pump, and the plugging meter, joined by 1 -in. pipe to form a rectangle comprise the loop. A tank 6-in. in diameter and 18-in. long fitted with an access port is the reservoir. This access port permits connection of the loop to a glove box to facilitate loading the loop with sodium or to add impurities. The total amount of sodium in the loop was $15 \mathrm{lb}$, of which $12 \mathrm{lb}$ were in the reservoir. The temperature control for the loop piping, reservoir, and plugging meter were separate. In operation, the piping was always maintained hotter than the reservoir so that no oxide would precipitate in the piping.

The electromagnetic pump had a capacity of $20 \mathrm{gpm}$ at $20 \mathrm{psi}$. Throughout the tests a flow rate of $0.1 \mathrm{gpm}$ was used during a plugging run.

During the cooling portion of the plugging run, air at a rate of approximately $5 \mathrm{cfm}$ removed heat at a rate of about $11 \mathrm{Btu}$ per min at a cooling rate of 50 degrees per minute.

The initial charge of sodium was $99.9 \%$ pure. No purification was done immediately, but the oxide coating was scraped off the $1-1 b$ bars. Prior to testing the plugging meter, sodium was circulated for several hours through the apparatus at $800^{\circ} \mathrm{F}$.

For the initial tests, the desired oxide concentration in the sodium delivered to the plugging meter was achieved by maintaining the reservoir temperature at the equilibrium value corresponding to the desired concentration. This effect was made possible because the initial charge was saturated with oxide at $900^{\circ} \mathrm{F}$ and the amount of oxide in solution (hence available to the circulating stream) was a function of reservoir temperature for values less than $900^{\circ} \mathrm{F}$.

A typical test included the following steps:

a) Heat the entire system to $800^{\circ} \mathrm{F}$ and circulate sodium for at least $4 \mathrm{hr}$.

b) Record plugging meter temperature and sodium flow rate as a function of time. 


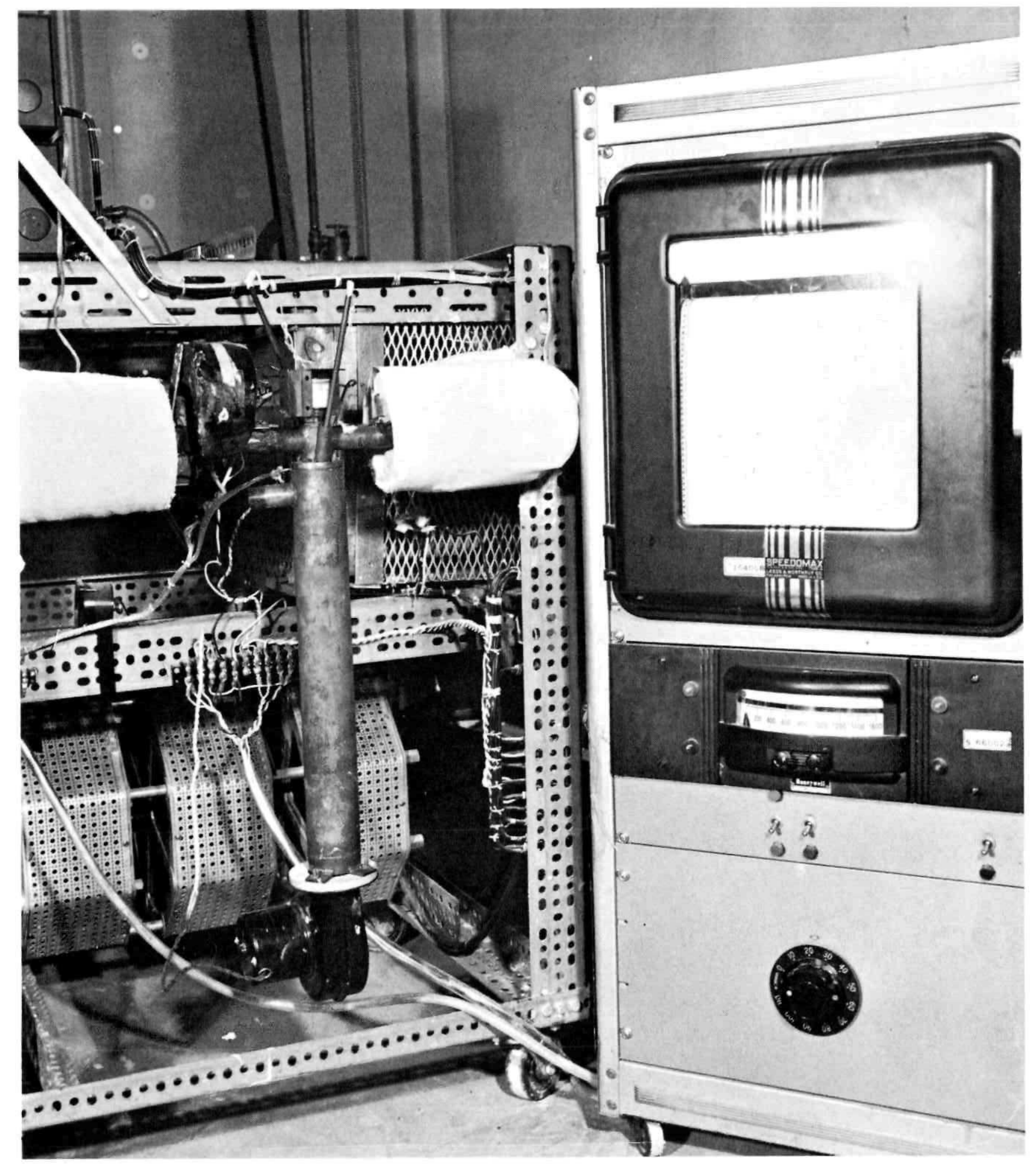

Figure 3. Plugging Meter in Test Loop 


\section{AI}

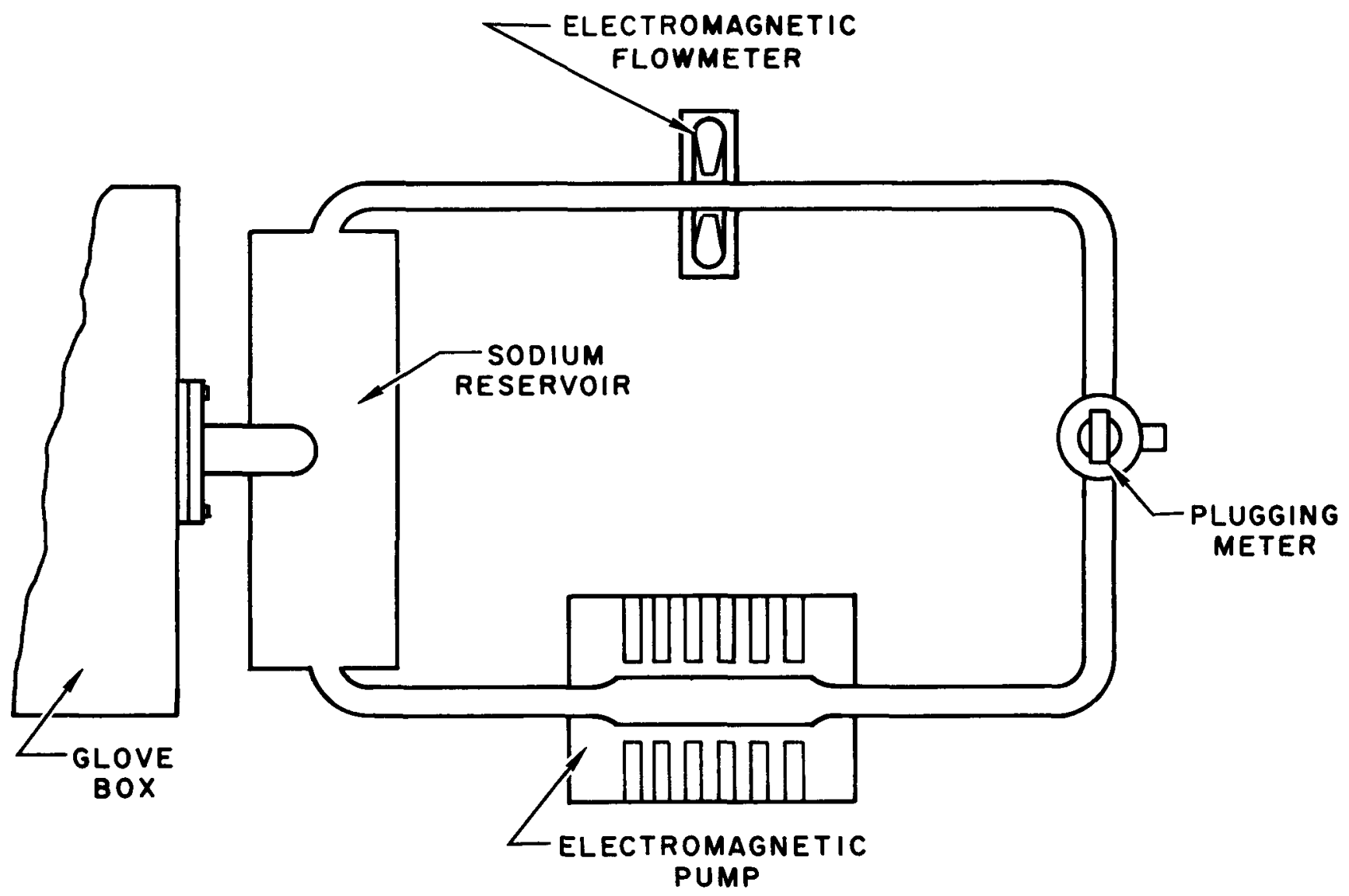

Figure 4. Plan View of Sodium Loop

c) Set flow rate of $0.1 \mathrm{gpm}$.

d) Set reservoir at the desired temperature and maintain constant over the test interval.

e) After all temperatures have settled at the desired values, turn off plugging-meter-heater and turn on plugging-meter-blower.

f) When recorder has given evidence that flow has stopped, turn off the blower, turn on the heater and open plugging-meter-orifice by energizing the solenoid.

g) When there is evidence that accumulated oxide has been flushed from the plugging meter, turn off the solenoid current to allow the central rod to drop into normal operating position for the next plugging run. 


\section{AI}

h) Determine the plugging-orifice temperature at which sodium flow began to decrease. (This is the plugging temperature. See Figure 5).

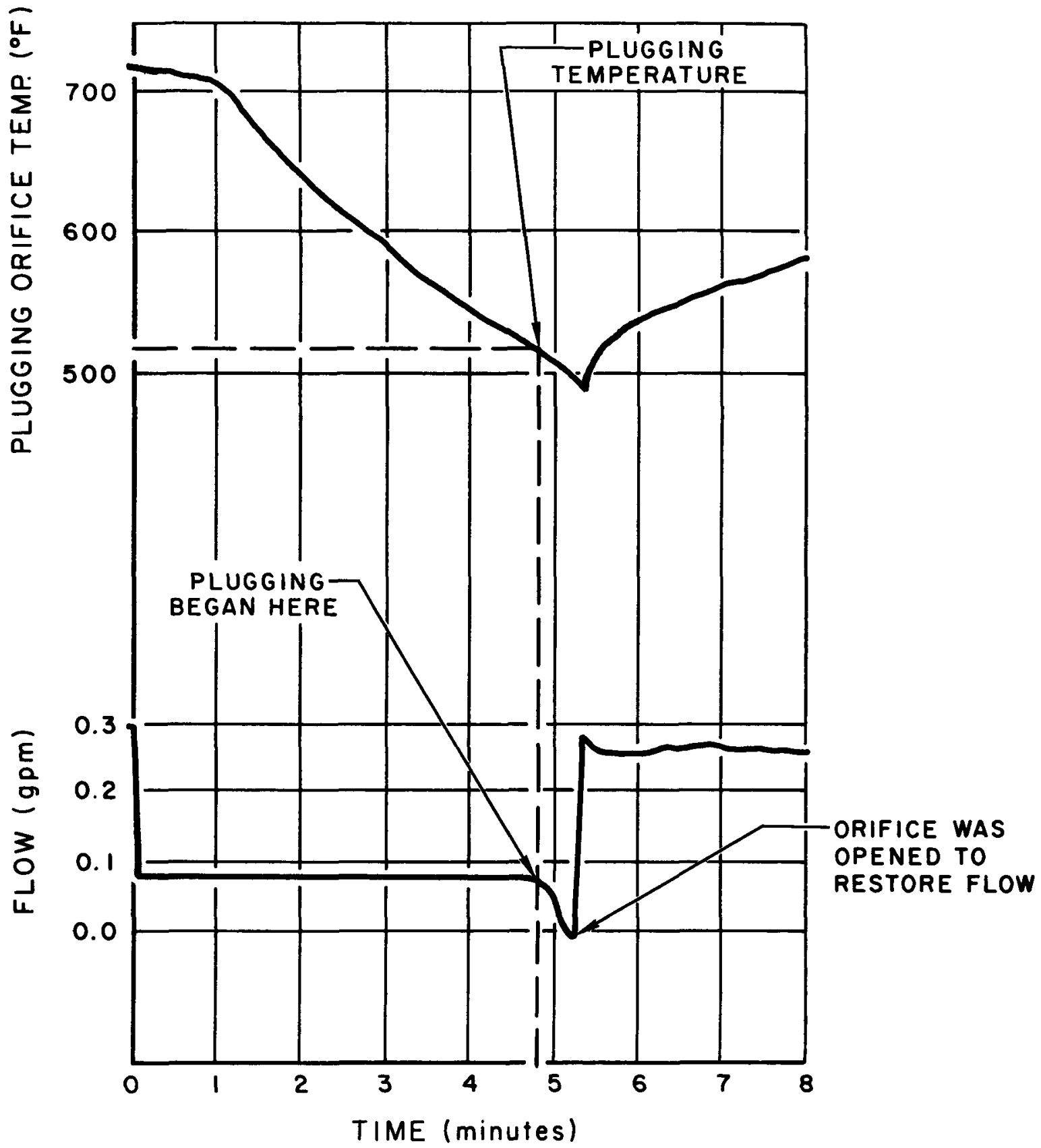

Figure 5. Recorder Display of Temperature and Flow in the Plugging Orifice Region 


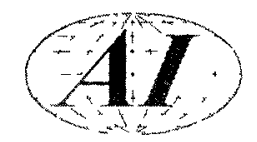

\section{RESULTS}

Many series of tests were run over a range of reservoir temperatures from the melting point of sodium $\left(208^{\circ} \mathrm{F}\right)$ to $800^{\circ} \mathrm{F}$. Altogether, approximately 200 plugging tests were performed on this plugging meter, and its operation was considered to be good since, with no sacrifice in reliability, its operation was easier and more rapid than that of other types.

A typical recorder display is presented in Figure 5. This shows the pluggingorifice temperature and flow as a function of time. The speed of plugging is evident; in this instance only 5 min were required. Likewise the unplugging is rapid, as shown by the instantaneous flow increase and the prompt temperature rise upon opening the plugging-orifice.

The values obtained in a typical series of tests a re displayed in Figure 6. These data were obtained by heating the sodium in the reservoir to $800^{\circ} \mathrm{F}$ and allowing it to cool in suitable decrements while plugging tests were performed.

To evaluate the effect of cooling rate and sodium flow rate on plugging, these were varied over a 3 to 1 ratio. Changing these parameters did not significantly change the plugging characteristics.

With this test method, the plugging temperature was expected to be equal to the reservoir temperature, since the reservoir temperature determines the amount of oxide in solution. In all cases the plugging meter temperature was consistently about $100^{\circ}$ lower, thereby indicating a lower concentration than was assumed to exist. A review of sources of error, such as faulty instruments, or poor placement of thermocouples, did not reveal the cause. The true cause of the discrepancy was not found, although if saturation were not reached in the reservoir (because of insufficient residence time for equilibrium solubility to be attained), there would be less oxide in solution than has been assumed. 


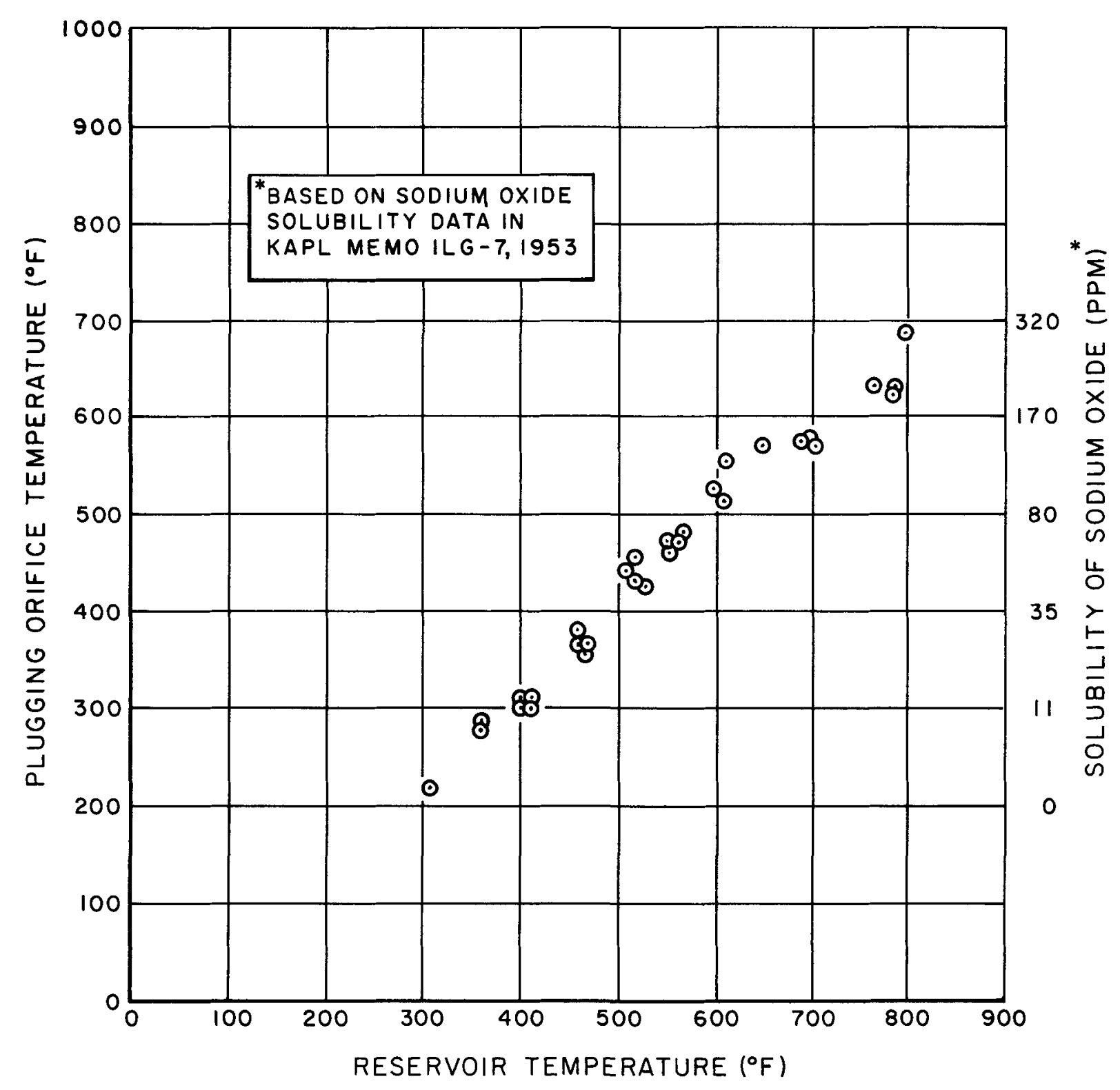

Figure 6. Variation of Plugging Temperature with Sodium Oxide Concentration 